\title{
Transcreation as a Way to Promote Employability in Translation Training: Adding Value to Translation Training
}

\begin{abstract}
An overview of the current professional translation industry shows that translation, in general, seems to be accommodating changes in the labor market and in society with relative ease. However, the scope, limits and boundaries of translation are a matter of academic and professional concern (Mayoral 2001; Tymoczko 2005/2007; Koskinen/Dam 2016; Dam et al. 2018), with some viewing the identity of translation somehow jeopardized by the great variety of professional translation-related services and practices encountered within the field (Gambier 2016; Koskinen/Dam 2016; Dam et al. 2018). It is true that services now associated with translation, such as technical communication (Risku 2004), transcreation, postediting or multilingual copyrighting (Mangell et al. 2019) are closely interrelated, sometimes even being identified as translation per se (Gambier 2016; Dam et al. 2018), despite the fact that no linguistic transfer even occurs. This paper will address the experience of trainee participants in a transcreation project developed at the University Pablo de Olavide in Seville (Spain). The project was an attempt to introduce transcreation, defined by the LSP industry as a service of added value, and initiate students in inventiveness and creative translation, while creatively enhancing translation graduates' employability (Rojo/Meseguer 2018: 79). Despite the assumed role of universities as providers of employability skills, this initiative also aims to add value to translator training, adopting an open, creative and boundaryless approach when dealing with employability issues in translators' training (Calvo 2010; Morón 2010; Kuznik 2016; Calvo 2018). The boundaries within and around the translation profession (Koskinen/Dam 2016) are tackled, through students completing simulated professional practice and self-reflection (Kiraly 2013/2016; Leggot/ Stapleford 2004a/b). A qualitative and analytical approach will be adopted, presenting the final assessment results from trainee participants during Stage 1 of project implementation, as well as real testimonies of graduates and professionals reflecting on the impact the initiative has on trainees' employability.
\end{abstract}

\section{Keywords}

transcreation; translator training; employability; entrepreneurship; simulated projects; situated learning

\section{Introduction}

Transcreation is undeniably gaining momentum within the translation field, both from a professional and an academic point of view. This may not be surprising today, given the digital age we live in, in which labelling, keyword planning, content marketing, and the rules of social media define global communication standards, and SEO/SEM practices influence the online content of any company on the World Wide Web. These new phenomena have also transformed the provision of services within the translation industry. Translation providers no longer define themselves as such; rather they call themselves Language Service Providers (LSPs), a label that seems to integrate diverse language-related services required by clients in physical and virtual markets. Therefore, LSPs still supply core translation and interpreting services, but also offer audiovisual translation, transcreation, localization, postediting, copywriting, revision and proof reading, intercultural advising, and up to 23 other translation related LSP services considered to be of added value (Pedersen 2014: 60; Calvo 2018). The focus of this study will be on transcreation as one of these

\footnotetext{
* Marián Morón Martín

Departamento de Filología y Traducción

Universidad Pablo de Olavide

E-mail:mmoron@upo.es
} 
services (Van Der Meer 2016; Mangell et al. 2019), and a matter of concern now within Translation Studies (TS) (Gaballo 2012; Reilly 2014; Pedersen 2014/2016; Østegaard 2015; Morón/Calvo 2018 , among others). It is our belief that the creative element as well as the interdisciplinary nature of transcreation, moving between the boundaries of translation and the marketing/advertising fields, lead to interesting issues in preparing graduates for work that are worth exploring.

At present, TS is trying to respond to the incorporation of transcreation, and as a result, some of the traditionally accepted theoretical translation concepts are now under scrutiny. Debate arises as to the translation-related nature of transcreation itself, because some standardized TS concepts cannot be easily transferred to the field of transcreation (Gaballo 2012: 96). Consequently, the concept and role of the source text (ST) or even the definition of translation techniques or strategies are now under examination (Østegaard 2015: ii). Moreover, transcreation workflows do not necessarily match those followed in traditional translation (Østegaard 2015; Morón/Calvo 2018; Mangell et al. 2019). Even the origin of the term seems controversial. Some believe that the term was first coined in the field of literary translation (De Campos 1969 in Milton/Bandia 2009: 259; Gaballo 2012: 97; Mangell et al 2019: 3; Munday 2013: 280; Sales 2004; Di Giovanni 2008: 34; Pedersen 2014; Østegaard 2015, among others), while others claim it was created within the translation of videogames (Ray/Kelly 2010), and then adopted by marketers and experts in international advertising to distinguish their particular field of expertise from that of standard translation (Mangell et al. 2019: 13). As Mangell et al. explained, they were assuming that "when bringing an existing advertising campaign to a market outside the source language; much more is needed than a translation"(2019: 13).

Regardless of its origins, the term "transcreation" has been adopted to address the translation (and language) processes taking place in international advertising and business marketing (Rike 2013; Pedersen 2014; Østegaard 2015). Some view transcreation as a distinctive translation service (Pedersen 2014/2016/2017); while others see it as a specific translation strategy applicable to any translation project requiring cultural adaptation (as in Malenova 2017 and Ketola 2018, in the field of audiovisual translation, or Musacchio/Zorzi 2019, in a corpus-based analysis of translated scientific texts).

Time will tell if transcreation is here to stay, but it is a fact that it has been listed among the current lists of LSP added-value services. The international standard ISO 17100 includes transcreation as one of the 23 added-value services in the LSP industry, considering that it involves far more than just translating (Calvo 2018: 19, 28). Undoubtedly, the market today requires the creation of alternative professional profiles, performing tasks that go beyond translation, as described by Van Der Meer (2016):

\begin{abstract}
The future does not need translators, at least not in the old way. [...] The future may not even need post-editors, as we see the MT engines getting better on the one hand and the audience becoming more forgiving for lesser quality of fast-moving content on the other hand. So, what do we need? By the time the lights in the old translation shop are switched off, what are the talents that we are looking for? We still need literary translators and 'transcreators' (don't expect MT to take on poetry, literature, marketing slogans and copywriting successfully). The human skills that a highly automated localization environment depend on are related to quality evaluation, content profiling, cultural advisory, data analysis, computational linguistics, and yes, on post-editing for the time being at least, but indeed less and less so on translating plain text. How universities train talents for the future of our industry is a topic that should appear high on our to-do list.
\end{abstract}

This paper will address a training initiative developed at the University Pablo de Olavide in Seville (Spain), under a teaching innovation program, within a four-year undergraduate degree in Translation and Interpreting, consisting in the implementation of a specific transcreation project as part of students' training in specialized translation. This initiative aimed at exposing students to the need to do something else other than just translating, working from an interdisciplinary and creative approach. The initiative was designed to simulate real transcreation professional practice (following the directives of Kiraly 2000/2016; Gouadec 2002 or Calvo 2015), making students reflect on the varying nature of transcreation (as compared to just translating) in terms of 
skills development and project management, while creatively fostering employability and career pathways inside and around translation (Koskinen/Dam 2016). We believe students benefit from this interdisciplinary and creative training experience, by making them reflect on the added value of transcreation, while also adding extra value to their training. We should highlight that no formal official training in transcreation is available right now in Spain among the nationally validated undergraduate translation courses (Morón/Lobato 2019), although some recent (private) training initiatives have been launched for specialization in transcreation. Anonymous online questionnaires have been used in order to gather student feedback and this paper will therefore adopt a descriptive methodology using qualitative research methods (Colás 1998; Hernández et al. 2003) to present and analyze the data collected. Finally, real testimonies of participants (professionals and trainees) who have forged their professional careers within the field of transcreation, either as freelancers or as communication and marketing company employees, will help us draw some conclusions on the career-oriented training required for translators today. It will also address future employability prospects for translation graduates.

\section{The added value of transcreation}

For the last decade, widespread materials have been released by LSPs in order to inform potential clients on the benefits of transcreation and its dynamics. With this objective in mind, corporate presentations, blog entries and general guidelines have been produced and disseminated for commercial and marketing purposes all over the world. In the year 2014, the international journal Cultus published a special issue entitled Transcreation and the professions, edited by Katan/ Spinzi (2014), reflecting academic debates around and within transcreation and translation in general. This included works developed in the fields of audiovisual translation, marketing translation, and translation identity, to name but a few. Research developed at Aarhus University has helped establish clear academic debates on transcreation (See Østegaard 2015 and Pedersen 2016 $\mathrm{PhD}$ dissertations as pioneer works in the field). Pedersen (2014) questions whether transcreation is "more than translation" and he presents some examples from expert LSPs defining transcreation. He qualifies transcreation as a service of added value when compared to translation (Pedersen 2014: 60), and he concludes:

\section{Phrases like 'more than translation' and 'just translation' seem to be repeated over and over again and contribute to the impression that transcreation gives an added value to a job that would otherwise be subject to translation.}

This consideration is also interesting taking into account that the LSP industry has already included transcreation among the list of added-value services they offer, along with sworn translation, localization, back translation, and others (Calvo 2018: 28). This reinforces the idea that transcreation is somehow different to translation per se, and something else is to be considered in the provision of transcreation services. In May 2019, the first official publication on transcreation from the LSP business was released, edited by members from recognized LSPs and international companies such as Nike, Burberry, and Alibaba ${ }^{1}$, among others, in addition to members of the international consortium TAUS (Mangell et al. 2019). This report aims at defining transcreation as a distinct professional LSP service, as compared to marketing translation, localization or multilingual copywriting. It also establishes some standards in the provision of transcreation services, which are generally not yet referred to in the quality standards of LSPs. Mangell et al. (2019) refer to the essential nature of transcreation as compared to translation, defining transcreation as:

A service that demands greater creativity: Pedersen (2014: 59) states that this extra creative effort relies on the difficulty of transcreatable texts, while Gaballo posits that transcreation is associated to

1 An interesting element to be further analyzed is the denomination of professional posts of the members of the editorial board in their corresponding companies; only one of them was named as "transcreator" and the others were holding posts such as Global Strategic Consultants, Global Localization Managers, Translation Managers or Localization Specialists. 
A service requiring a different workflow, with teamwork, brainstorming sessions, client negotiation and the provision of different alternatives, together with back-translation, as key stages of a transcreation project (also in Pedersen 2014: 60). Pedersen explains that this different work process is needed to "transfer brands and messages from one culture to another", where efforts must be made to produce a given brand language and style adapted to the target culture. Consequently, different work units and quoting elements need to be considered (Morón/Calvo 2018; Mangell et al. 2019).

Some researchers shed light on the fact that the industry sets concepts and standards that are later directly assumed by the academia (as in Pedersen 2014 or Gaballo 2012), challenging researchers in this respect. From the description above, the added value of transcreation seems to be determined by its interdisciplinary nature. Transcreation seems to emerge where other disciplines meet (translation and international or technical communication, advertising and marketing), requiring the adoption of the so-called "this is not mere translation" approach in an attempt to conceptualize transcreation (Gaballo 2012; Rike 2013; Pedersen 2014; Østegaard 2015; Morón/ Calvo 2018; Mangell el al. 2019, among others). However, its complex nature has not been deeply and systematically explored yet. Some authors and practitioners debate whether transcreators are merely good translators, while others seem to stress that the particular elements of transcreation require special knowledge and skills. So far, no specific models have been developed as to the specific skills set transcreators need to rely on. Nevertheless, Mangell et al (2019: 14) emphasize some discipline-bound elements to define transcreators' skills, more specifically in terms of field knowledge and expertise in marketing, combined with creativity in the adaptation of messages for a given target market. From this, one may conclude that a deep understanding of interculturality is fundamental in transcreation to assess, and strategically decide on, potential interventions in adapting any culture-bound elements or brand image elements (also culture-bound) to the target market. In the absence of specific skills descriptors, our focus would be on the added value of transcreation as compared to translation, which seems to be more clearly established.

Finally, the TAUS report suggests further efforts on the part of the academic community to tailor programs to the specificities of transcreation. By highlighting the words in the paragraphs above, the added value of transcreation is emphasized. In addition, to serve our research objectives, these elements also help us explain the added value of the training experience presented here. This is aimed at meeting market demands for greater creativity and adapting work processes in order to train professional transcreators and enhance graduates' employability.

\subsection{Training employable transcreators: The TeCreaTe project at UPO}

The TeCreaTe (Translation in e-creative digital environments) has been in progress for 3 years now at the University Pablo de Olavide in Seville (Spain) (UPO), under the umbrella of the continuous innovative teaching programs by the UPO Vice-Rectorate of Teacher Training. As dealt with in Morón/Calvo (2018), the rationale of the project is explained by the following elements:

1. It consisted in the design of professional simulation projects in transcreation, included as part of the continuous assessment in the fourth and final year of the English-Spanish specialized translation module (also developed in the French-Spanish third year specialized course), where students were encouraged to act as real LSP professionals in transcreation tasks requiring transcreation or revision of already translated materials to evaluate their transcreatable potential. Simulated student agencies respond to the profile of the TeCreaTe project professional cooperators, described in paragraph 4 below. Between 3 and 4 English-Spanish transcreation tasks were produced, including the transcreation of text contents from a marketing campaign and the slogan and hashtag originally used in English in the source cultures and markets, online catalogues, and website materials disseminated by different brands (TeCreaTe simulated clients) via their official corporate webpages (See Morón/Calvo 2018 and Morón/Lobato 2019, for further details). Projects consist of less than 2000 words to be transcreated in total, as the focus (in terms of learning objectives) was put on the process and the implementation of 
the whole workflow and project management stages of a transcreation project, in order to better grasp transcreation's special features and its added value. Students were encouraged to develop professional competences and knowledge, and a better understanding of today's LSPs' labor market, in general, and transcreation, in particular.

2. Training tools were designed with the collaboration of transcreation experts. A battery of instruments was produced, from transcreation briefs to directions on project management (teamwork, time and resources allocation, invoicing, and so on) for proper project implementation. Regarding invoicing, students received some further reference materials, taking into account that invoicing in transcreation is carried out by the hour, and not by the word (the standard in translation tasks students seemed to be more familiar with), and that some extra creative efforts were required from trainees. In this sense, students were asked to provide cultural advice to the simulated client on the potential elements to be localized in the target market (i.e.: potential designers, sponsors, calendar events in Spain for a smooth launch of the campaign in the target market, etc.). Trainee transcreators served as intercultural mediators (Katan 2016: 376), trying to accommodate the "transcreational turn" Katan (2016) proposed, and facing them with new "risks" and tasks beyond language transfer (Mangell et al. 2019). Reflection was promoted so as to the impact of these requirements in (future) quotations and invoices.

3. Due to the number of students in class, which ranged from 20 to more than 60 per student group, work was organized into teams (of 5 to 7 students per group), in an attempt to stimulate creative thinking and the exchange of ideas. Oral presentations were also required to make students reflect and justify their transcreation decisions before the simulated client (the trainers). These features were aimed at reproducing real working conditions of transcreators (Pedersen 2014; Mangell et al. 2019).

4. Professional collaborators from interdisciplinary fields joined Stage 1 (see description below), first as mere advisors and trainers of teachers and students, and then as expert assessors of students' work (Stage 2). They were professional transcreators (freelancers and in-company transcreators, such as Tatutrad.net ${ }^{2}$, a well-established translation and transcreation company from Seville, and other freelance transcreators, such as Oliver Carreira ${ }^{3}$, who is completing his $\mathrm{PhD}$ on transcreation at UPO under the supervision of Dr. Calvo, project co-designer and facilitator; and some alumni who have specialized in transcreation) and marketers: INNN.es (from Seville, Spain) and NoSoloUnaIdea (Granada, Spain), marketing, copywriting and communication agencies. It is worth noting that the professional transcreators cooperating in the TeCreaTe initiative also facilitated samples of real transcreation projects and briefs (dully respecting confidentiality agreements), essential for the design of relevant training materials, tailored to actual market needs.

So far, three different implementation stages can be determined, matching various project objectives in terms of career-oriented transcreation training:

- $\quad$ Stage 1. Diagnosis, implementation and assessment by those taking part in the projects (2016-2017). During Stage 1, the TeCreaTe project was designed and adapted for implementation in groups of English-Spanish (63 final fourth-year students) and French-Spanish (18 third-year students) specialized translation students. Stage 1 aimed to explore trainees' expectations and skills development, with a view to exploring boundaries in terms of future employability, as will be explained in section 5 . The results of this paper are based on the assessment of the English-Spanish translation student group, who were about to complete their degrees and, hopefully, enter the labor market.

- $\quad$ Stage 2. Assessment by professionals (2017-2018). During this second stage, results gathered thanks to the different transcreation solutions were submitted for assessment by a team of expert professionals, in order to explore quality assessment and reception of transcreated texts.

- Stage 3. Transcreation processes: back-translation (2018-2019). The most recent project stage helped analyze some project stages in more depth, such as the back-translation stage, which revealed interesting issues for future research (see some recent works on back translation by Bundgaard/Brøgger 2017/2018) 


\subsubsection{The added value of transcreation in translator training: boundaries within and around (Koskinen/Dam 2016) for future translators' employability}

As established above, the focus of the TeCreaTe initiative was transferring transcreation added value, as conceived and implemented in the profession, to translator training. Here, trainers were looking at gaining greater creativity and incorporating new dynamics, in terms of working processes in the simulated practice of transcreation in class, with the objective of responding better to market needs, hence improving future employability prospects for trainees.

In this respect, the TeCreaTe project addressed the boundaries (professional and disciplinary) within the profession, as expressed by Koskinen/Dam (2016). Here, issues related to the status of the translation profession were dealt with, trying to address the assumed added-complexity element of transcreation as compared to standard translation. It also considered the extraordinary efforts to be made by transcreators, and the differences between the roles of these two professional profiles within the translation industry.

On the other hand, the boundaries affecting the profession were also tackled. Here, students were encouraged to assess interdisciplinary training opportunities, as well as future employment prospects in related disciplines, empowering subjects to make the most of their translation-specific skills when migrating to other disciplines (Risku 2004; Calvo 2010; Morón 2010; Morón/Medina 2016), and favoring translation competence transferability (Calvo 2010).

As will be explained in the research methodology, these elements were achieved by exposing students to real (simulated) experiences which had been designed, and promoting reflection on the specificities of transcreation briefs and the work produced (through final assessment questionnaires).

\section{Research methodology}

The data presented here is based on the results of the final reports gathered from trainee participants during Stage 1 of the TeCreaTe project implementation. An anonymous online questionnaire, designed using the GoogleForms $\odot$ platform, was submitted to participants so they could provide feedback and give their final assessment on the TeCreaTe training experience. Researchers were aware of the limitations of using Google instruments for data research and analysis. However, due to the exploratory and qualitative nature of our research, the instrument proved useful for the purposes of the study. Questionnaire dimensions (QDs) consisted of:

QD1. Student profile: basic information on the trainees' profile (age, sex and language combination).

QD2. Self-assessment of students' creative profile: following the instrument "Runco Creativity Assessment Battery" (rCAB) C), designed by Runco (2012) from the University of Georgia (USA), who after contact, advised project developers on the implementation of the tool. Here, students were encouraged to perform a self-evaluation of their own creativity. Interpretation of this research dimension, also facilitated by the $\mathrm{rCAB} \subset$ tool, would require a more in-depth analysis beyond the scope of the present study. However, some general conclusions on the creative profile of participants will be considered for data analysis and interpretation.

QD3. Previous training and professional experience in translation and transcreation. In order to complete trainee profiling, the interdisciplinary nature of translation and transcreation involving cultural-bound activities was considered. This led to questions aimed at observing students' previous experiences that may have an impact on the professional (added value) profiles to be developed in transcreation. Consequently, questions addressed the following:

- Students' previous contact with the Anglo-Saxon-culture (i.e. academic mobility in English-speaking countries), to approach the target culture and intercultural skills (Kelly 2002, 2005).

- Students' previous training experiences in translation and/or other non-translation neighboring fields (i.e. marketing, business, advertising); and 
- Students' previous training in transcreation.

QD4. Previous training and experience in the development of professional translation/transcreation skills. Here, given the simulated nature of the project, students were asked about previous training for the development of professional skills (both translation-specific and/or transferable to other fields), such as teamwork, problem solving, decision-making, creativity, and project management skills.

QD5. Feedback on the experience in the TeCreaTe project: overall assessment of the training experience.

QD6. Immediate plans in terms of employability and job immersion: here two elements were analyzed:

\footnotetext{
- Students' employability expectations, inside or around the translation profession (Koskinen/Dam 2016, Dam et al. 2019), and

- Students' willingness to work and/or complete their training within the field of transcreation.
}

The questionnaire included closed and open questions. Close-ended questions were used in QD1 and in some questions including Likert-scale responses, based on the specialized literature and expert trainers' and collaborators' experience, to gain richer responses on trainee perceptions from a qualitative point of view (QD2-6). Open-ended questions were reserved for collecting students' personal responses and additional feedback on the training experience in general (QD5-6). Trainers informed participants that the TeCreaTe project was an innovative teaching initiative and they were encouraged to participate in the final survey on a voluntary basis for future project improvement. More than 100 students participated in the project during Stage 1. Around 17\% were French-Spanish third year translation students, and the rest were English-Spanish undergraduate students from the specialized translation course.

The results presented here will be analyzed from a qualitative and interpretative perspective to reflect student and expert participants' perceptions on students' gains in terms of professional skills development and graduate employability.

\section{Results from the transcreation experience in terms of students' employability skills}

Following a triangulation scheme, the analysis of results provided in participating students' questionnaires will be accompanied by testimonials of former trainees who, after joining the labor market, have provided us with an insight on the impact the TeCreaTe experience has had on their career development, from their own point of view. Further testimonies on the part of expert professional assessors will also be incorporated in the analysis. These testimonies are considered of utmost importance, as they represent the nature of the TeCreaTe training experience as an addedvalue experience in their translator training. Finally, authors will draw some conclusions based on their observation and in-depth study in terms of participants' professional development and employability in translators' training.

\subsection{Results from participating students' questionnaires}

Up to 81 students completed the online final assessment instrument (out of more than a hundred who joined Stage 1). Despite this general positive figure in terms of survey subjects' participation, we consider our sample to be qualitatively representative (Sierra 1998), so statistical data will only be used as a description of trends in the responses facilitated. The qualitative, descriptive and exploratory nature of the study needs to be taken into consideration for data interpretation. However, this participation figure did not seem to correlate to the interest expressed by participants in class. From the 81 Stage 1 participants, $77.8 \%$ were English-Spanish translation students (63 students - our sample in the present study). All of them were translation students in their 
final year of undergraduate Translation studies at UPO. 85.7\% were female, and most were aged between 19 and 21 years old, an age range generally expected for final year Spanish translation undergraduates.

Students' native language and nationality were Spanish in 95.2\% of the cases, with three students having Italian language and nationality. These were on an Erasmus student program at UPO and were studying Spanish as their first foreign language at their home institutions ${ }^{4}$.

In the initial presentation of the project, discussion arose in class as to the difference between transcreation and other translation services, mainly localization. Most of the participants admitted they had not heard about transcreation before the TeCreaTe experience, and initially felt underprepared to tackle professional simulation tasks in transcreation, with many doubts about the nature of the transcreatable texts.

\section{Cultural awareness: previous contact with source cultures}

Cultural awareness is a complex matter to address. Defining cultural awareness in transcreation was not a goal of the study, so students were only asked about their cultural knowledge and preparation to tackle transcreation tasks. Here, they were asked about previous contact with AngloSaxon cultures, as English was the ST language. $55.6 \%$ of the 63 survey subjects had participated in some mobility experience in English-speaking countries both for personal and academic reasons, and 28.6\% had experienced some time abroad in English-speaking European countries prior to attending university. $15.9 \%$ stated they had taken part in university academic mobility programs in English-speaking countries during their translation undergraduate degree training. However, in most cases, the experiences reported amounted to less than 4 months, with only around $8 \%$ of the sample reporting mobility stays between 4-6 months. This data seems to correspond to the standard one-term mobility experience for university undergraduates in the framework of the Erasmus + mobility scheme.

Around $28.6 \%$ of the students in the sample had never experienced any mobility experience in any English-speaking country at all, neither before nor during their university training. This seems quite shocking to researchers, considering project participants were all final year students of English-Spanish specialized translation. This finding also poses some interesting research questions as to the cultural knowledge and experience of translation students (See Kelly 2005, Soriano 2007, Morón 2010, on the value of mobility in translator training in terms of translation skills development). Therefore, in most cases, cultural awareness seems to be restricted to the declarative knowledge students may have acquired thanks to academic training, self-study, reading and access to any other sort of cultural product (films, series, plays, etc.), and less to actual immersion in the ST cultures.

\section{Interdisciplinary training}

Around $70 \%$ of the 63 survey subjects stated that they had been trained in different translation specific domains, namely in IT, legal, technical, commercial or scientific translation, and localization. These results seem to correspond to the local academic offer of translation modules and subjects that are compulsory for students. Around $8 \%$ referred to some training in postediting and another $8 \%$ included other areas of specialization. However, for most of them, their previous training in transcreation was restricted to the one received within the framework of the TeCreaTe project. Only two subjects had followed external training in transcreation before the TeCreaTe initiative. One of them completed a course in a private company, and the other was an Erasmus student who followed some transcreation courses at the local institution. Moreover, more than $60 \%$ of the subjects consulted confirmed they had never followed any training initiative in any non-transla-

4 This group of non-natives were distributed among Spanish native groups for project implementation, as work in transcreation is normally carried out into the mother tongue (Spanish in the TeCreaTe project), with in-depth cultural adaptations to the target market (again, Spanish) required. 
tion specific fields. Bearing in mind the interdisciplinary nature of translation (and transcreation) and the value of interdisciplinary skills in TS (See Aguayo's full review, Aguayo 2017), the sampled students' training profiles seemed to be exclusively translation discipline oriented.

\section{Creativity and assessment of transcreation degree of difficulty}

In relation to their creativity, participants observed that they lacked creative or novel personality traits following the $\mathrm{rCABC}$ test. As explained above, these elements have not been fully incorporated in our research so far, as some specific additional variables would require an in-depth study of students' translation creativity, including expert advice from psychologists. Nevertheless, and by way of a preliminary overview to this research dimension, students' self-perception of difficulty was analyzed in contrast with self-assessment of their creative personality. Here, it was observed that the tasks requiring greater creative effort (namely those requiring the creation of slogans and hashtags to be adapted to the target culture) were rated as more difficult by our survey subjects. It is our belief, in this preliminary research, that when performing creative tasks requiring different procedural efforts (beyond merely linguistic transfer processes), in which their habitual behaviors were challenged, students' perception of difficulty was increased.

\section{Market-oriented training goals}

Regarding their preparation for simulated tasks, almost $67 \%$ of the sample claimed they had not received any previous training in working on professional simulation projects. Despite that, students felt prepared to embark on transcreation projects, relying on their linguistic skills $(97 \%$ agreed or fully agreed on this), their communication skills (92.1\% of the sample fully agreed or agreed), and the production of reference materials designed and facilitated by TeCreaTe trainers ( $90 \%$ in agreement or full agreement). A lesser number of students considered their cultural awareness as enough to tackle transcreation projects (77.7\%), followed by their knowledge of professional translation $(66.7 \%)$ or their previous professional experience (27\%). Their professional experience was actually very limited, as one may expect from undergraduate students. However, they reported some professional work experience in technical translation (for 19\% of participants, producing a maximum of 9 translation projects), commercial translation (around 13\% producing between 2-5 professional projects), and audiovisual or literary translation (both with $11 \%$ of sample subjects having carried out between 2-5 remunerated projects). Students agreed or fully agreed that the most valuable elements of the TeCreaTe project for their future professional development were: 


\begin{tabular}{|l|l|}
\hline & $\begin{array}{l}\text { Agreement } \\
\text { Total agreement }\end{array}$ \\
\hline $\begin{array}{l}\text { Participation of experts as assessors in the project, } \\
\text { during Stage 2 }\end{array}$ & $93.6 \%$ \\
\hline $\begin{array}{l}\text { Multimodal project work, including advertising and } \\
\text { marketing materials in different formats: text and } \\
\text { images }\end{array}$ & $93.6 \%$ \\
\hline Real simulation task & $93.6 \%$ \\
\hline Project including, but not limited to, translation tasks & $90.5 \%$ \\
\hline $\begin{array}{l}\text { Incorporation of specific training in transcreation } \\
\text { (seminar by expert transcreators and marketers) }\end{array}$ & $90.5 \%$ \\
\hline Pioneering experience & $90.5 \%$ \\
\hline Innovative teaching experience & $88.9 \%$ \\
\hline Participation of transcreation experts & $88.9 \%$ \\
\hline Participation of advertising and copywriting experts & $87.3 \%$ \\
\hline Revision of real translated materials & $79.4 \%$ \\
\hline Oral presentations & $79.4 \%$ \\
\hline Inclusion of materials from the fashion industry & $74.6 \%$ \\
\hline Teamwork & $68.2 \%$ \\
\hline
\end{tabular}

Table 1. The most valuable elements of the TeCreaTe project for participants' future professional development

Open-ended responses collected addressed the value of real simulation tasks where students were required to go through the whole transcreation process. This encompassed interpreting the initial brief, client negotiation and teamwork for project implementation, and concluded with the final invoicing of the project. In fact, they welcomed the inclusion of simulation projects in their training.

As immediate gains from their participation in the TeCreaTe project, surveyed subjects claimed that they were more aware of the complexity of translation processes and the work they may be able to develop in non-translation specific jobs $(98.4 \%$ showed their agreement or total agreement with this assertion). They also boasted greater awareness of their own translation profiles, being more conscious about their own professional strengths and weaknesses in their work as translators (90.5\% agreed or totally agreed). They also claimed to be more aware of the particular features of transcreation as compared to other translation-related services (98.8\% agreed or totally agreed) and they felt, in general, better prepared to tackle professional projects in translation $(92.1 \%$ in agreement or total agreement). In contrast, only $87.3 \%$ of survey subjects felt ready to work as professional transcreators immediately, maybe since this was the first experience in transcreation for most participants.

They were satisfied they had become more aware of the value of teamwork $(90.5 \%$ expressed agreement or total agreement) and the role of documentation in the translation process $(93.6 \%$ agreed or totally agreed with gains in this area). Participating students also considered their creativity to have been developed thanks to their participation in the project (with $88.9 \%$ expressing agreement or total agreement), but around $25 \%$ of the sample subjects demanded some additional 
training in the technical and procedural elements surrounding the provision of transcreation services, such as quoting or invoicing. Here, they required some extra effort on the part of trainers in providing clearer instructions in the briefs (around 16\% considered them to be deficient). A few of them also demanded further reference materials, which were considered insufficient by $5 \%$ of the sample. In their final comments, students recognized and understood that the extension of the project (less than 2000 words) did not seem to correlate to its degree of difficulty, due to the variety and complexity of tasks developed and their variety, and the creativity efforts required, beyond mere language transfer. Finally, participants welcomed the introduction of the TeCreaTe project for the training of transcreators and translators, in general.

\title{
Areas for future employability
}

Despite their previous limited knowledge on transcreation, after participating in the TeCreaTe project, students recognized their willingness to pursue careers, not only in transcreation and localization (around $75 \%$ of the sample), but also in marketing translation (73\%) and audiovisual translation $(63.5 \%)$. In a preliminary consultation in class, students considered localization and audiovisual translation as the focal point of their future employment interests. All in all, students reported their willingness to continue their training in transcreation, with $75 \%$ of survey subjects who agreed or totally agreed on pursuing further training in this area, and $90 \%$ would recommend or totally recommend the TeCreaTe project to future students.

The following comments, given as responses to the open-ended questions, help us appreciate students' satisfaction with their training experience, and the fact that they valued the opportunity to open themselves up to some other areas of future professional development, beyond translation-specific domains 5 .

\footnotetext{
"It has been a memorable Project and (...) very stimulating. Never before has any course challenged our skills and creativity in such a way. I enjoyed it so much, I have just started a training course on transcreation and copywriting on a voluntary basis and am doing it in parallel with my final year subjects. I hope to learn a lot more and I aim to pursue a career in this field as a professional. In the meantime, I firmly believe that the TeCreaTe project has been a great way to introduce me to the field".
}

Another student also commented:

\begin{abstract}
"It (The TeCreaTe project) has been the most inspiring initiative I have experienced during my undergraduate career. This includes every aspect: creativity, involvement of team members and complexity. I wholeheartedly thank the teachers for introducing us to transcreation. I now consider this as an alternative for my professional development."
\end{abstract}

These comments raise many interesting issues to be considered in terms of enhancing graduates' employability and promoting professional-oriented approaches in translators' training that will be discussed in the conclusions that follow.

\subsection{Data gathered from graduates and external expert assessors: some insights from inside the profession}

Stage 3 of the TeCreaTe project is currently underway and additional research objectives have been incorporated in order to delve deeper into students' and graduates' employability and entrepreneurship in the field of transcreation and professional translation. Some initial conclusions can be drawn from the experience and evaluation of participating experts (in Stage 2). Their feedback is essential in order to achieve our goal of providing meaningful training opportunities, tailored to market needs. Expert participants welcomed the TeCreaTe initiative, and they were committed and willing to collaborate and encouraged further work on the part of trainers in terms of graduates' employability. The following comment provides an example of experts' positive feedback:

Testimony 1. Expert assessor 
“(...) I have just completed the assessment module for the Topshop commercial campaign for Spain.

(...) I am very pleased to have had the opportunity to participate, I found it very interesting, well designed and... I wish I'd had the chance to learn things like this at university! I think you are doing an excellent job in preparing future "transcreators". (...)

Finally, a line of communication with former participants was established via the Facebook ( alumni group. Thanks to this, we are collecting feedback from graduates on the impact the TeCreaTe training has had on their professional careers. We acknowledge that we are not gathering data in a systematic and scientific way so far, but the fact that graduates in the labor market decide to contact trainers, on a voluntary basis, to tell us how much they value their TeCreaTe training is encouraging for both trainers and researchers in translators' training. We provide two of these testimonies from graduates. It is worth noting that testimony 2 comes from a graduate who has migrated to the field of international technical communication within the marketing and advertising business (as in Risku 2004), and testimony 3 is from a graduate working in the field of creative marketing translation projects.

Testimony 2. Graduate (1)

"Hi (Name of trainer)!

It's been a while (...)

The first thing I would like to say is thank you for guiding me with my career. I had no idea what to do, until I got to the final year of my studies and discovered the wonderful world of copywriting! I am now living in Madrid as content producer working for a start-up company, and here I am, working in copywriting and as a UX writer in different languages. So, I can finally say - I've achieved my goal!

It's crazy to see how positive and attractive language can lead to such significant sales increases! And all of this is thanks to you! (...)"

Testimony 3. Graduate (2)

"Good afternoon, (Name of trainers).

I am (Name of respondent), and I am very happy to email you to tell you how I am doing... In less than a month, I will be moving to Madrid to do an internship in subtitling for a well-known company. (...). I am very excited about this new experience, as I guess it will help me broaden my horizons and become fully integrated in the labor market. Moreover, I am delighted to tell you that I am currently working in the translation of sales materials for selling carpets, and I am constantly referring back to the work we produced in the transcreation project. I really enjoyed it as a student, and now I am delighted to have the opportunity to work on a project of this kind. (...)".

Of course, time framework limitations cannot be overlooked. These testimonies were collected less than a year after graduation, but even then, they demonstrate the easy access these two subjects have had to the labor market, both inside the translation profession or in some other related area. Again, it is unquestionable that defining and being able to measure the real impact of training initiatives in graduates' careers and employability requires a more in-depth and proper scientific study. This, however, was not the aim of this exploratory study. Nevertheless, the experience and positive assessment from students, graduates and expert collaborators seem to reinforce the elements of added value that were set as primordial goals of the TeCreaTe initiative.

\section{Preliminary conclusions in terms of students' professional-oriented training and graduates' employability}

The efforts to provide a definition of transcreation reveal distinctive features and particular processes that qualify the service as an added value translation service within the LSP business. When incorporating transcreation training in translation training programs, as is the aim of the TeCreaTe project, it is assumed that some extra value is also added to students' training experiences. 
On the one hand, the TeCreaTe project reproduced some standard teaching and training practices that have proved beneficial in terms of professional-oriented guidance and preparation. Project simulation, the involvement of practitioners and trainers, plus a student-centered approach where execution and reflection are fostered (Kussmaul 1995; Kiraly 2000/2005; González-Davies/Scott-Tennent 2005; Kelly 2005; Tymoczko, 2007; Way 2008; Calvo 2015, among others) were all welcomed by trainees and considered essential by expert assessors for meeting real market demands. It cannot be overlooked that sample subjects gained some real work experience, even before graduation. By providing professional services while receiving training, this preparation becomes essential.

In addition, research on skills acquisition reveals that subjects need to experience competence for competence to emerge (Kiraly 2013). Moreover, it seems evident that subjects encounter some problems in identifying their own competences and skills (Leggot/Stappleford 2004a/b; Aneca 2006; Calvo/Morón 2006; Way 2008). Hence, experience and self-reflection opportunities are essential, and they seem to add value to the overall training and learning experience of students, as TeCreaTe participants' feedback illustrates.

The inclusion of the creative element is crucial in translation training in general, and in transcreation in particular, where content is creative by nature (Pedersen 2014: 60). This is the case of advertising slogans, or even hashtags used today in social media in order to market and promote sales of a given product or service. Research on creativity has shown that creative skills are also fostered by experience (Ericsson 1998; Reilly 2008; Boysen 2015), linked to emotional intelligence, but also to decision-making and problem-solving skills (See the review presented by Rojo/ Meseguer 2018). In fact, encouraging creativity requires in-depth field knowledge and expertise, and the mastering of a given domain (Ericsson 1998; Reilly 2008; Rojo/Meseguer 2018). Truly, one cannot assume students' mastery of the field, but this can be facilitated by providing simulated tasks, with expert collaboration and feedback, providing a "secure" experimental environment as a laboratory for (future) skills development.

Despite the fact that transcreation skills were not an aim of the present study itself, researchers were analyzing the way to provide trainees with better academic tools to fulfil current professional profiles, such as that of the transcreator (Van Der Meer 2016). Some preliminary conclusions can be drawn so far from our exploratory study. As expert translators' trainers and researchers in TS, a set of marketable skills were detected and addressed to reflect the specific added value of transcreation. Transcreation added value seems to be defined by the need to execute tasks with greater creativity, which would require some strategic translation components for the detection of translation and transcreation problems, together with subsequent problem solving. Then, culturebound awareness factors (which would be worth analyzing due to the limited cultural immersion experienced by our survey subjects), and a whole set of technical and professional transferable skills (teamwork, decision-making, etc.) appear to be necessary to tackle a process that seems different to the simple translation process (Mangell et al. 2019). These elements are also highlighted as explanations for the added value assigned to transcreation. Transcreation skill components, however, do not seem to differ that much to the ones set in the most-recognized translation skills (Kelly 2005; PACTE 2014; EMT 2017) from the preliminary and observational study developed. However, the transcreation process may differ significantly, and the varying effort required for each of these components for good quality execution in transcreation would require in-depth future study. While experiencing transcreation tasks, students were able to experience specific translation skills tailored to the practice of transcreation. Here, brief analysis, the effects of directionality in some transcreation project stages (i.e. in back-translation), revision processes, the justification of transcreation decisions and quality assessment, are all examples of the major elements to be considered, as compared to traditional translation-specific processes. This closer look at the actual practice of transcreation also enables a more in-depth approach to translator training, from our point of view. 
From our preliminary findings, it was observed that processes requiring work beyond linguistic transfer led to an increase in students' perception of difficulty. This was the case with tasks entailing the design and justification of commercial marketing material compared to the commercial brief provided. It seems that the extreme instrumental translation approach (Nord 1991) required in transcreation also demands greater creative efforts, not only related to production of the endproduct, but in terms of process implementation. Therefore, some students were demanding clearer instructions in the briefs to support their decisions, as they were not used to understanding strict commercial briefs, rather translation briefs. Further study in this area would be also welcome in order to better conceptualize both the transcreation service and its implementation (Calvo 2018), especially in terms of quality assessment, an element to be closely looked at.

The inside boundaries (Koskinen/Dam 2016) of the profession are addressed by making students experience, value and reflect on the specific skills and processes required in transcreation as part of the translation profession. Moreover, the interdisciplinary nature of transcreation has given rise to interesting elements to reflect on regarding employability issues, not only from the perspective of the translator as an insider (from inside the translation profession), but also from the point of view of the translator as an outsider. From this perspective, translation is observed from the viewpoint of neighboring areas, addressing some key procedures of other disciplines (marketing, technical communication, and so on). This involves adopting new interdisciplinary profiles and favoring employability opportunities outside the translation field. Here, translators' valuable professional skills (Risku 2004; Kuznik 2016; Morón/Medina 2016; among others) and the transferability of translation skills (Calvo 2010) are considered valuable employability assets, as the market seems to be requiring linguistically-able professionals to operate in international and intercultural markets (European Commission 2005). Risku (2004) explored the migration of translators to the field of technical communication and produced an interesting study on the shared skills background of these professionals. The opportunity to reflect on translation skills transferability (Calvo 2010) and the role of translation transferable skills (Kearns 2008) presents a positive element and added value when included in training (Morón/Medina 2016). This seems especially interesting when (Spanish) translation students do not necessarily access translation studies with the motivation (nor even with the willingness) to become professional translators (See the works of Calvo 2010 and Morón 2010, providing in-depth study of translation students). On the contrary, they see translation simply as a way of accessing careers where language, cultural interactions and international professional mobility play an important role (Morón/Medina 2016; Morón in press).

Our approach is open in nature, willing to reflect research on the disciplinary and professional boundaries of translation, and the fact that professional translation careers seem to develop beyond pre-determined professional or disciplinary boundaries (See Risku 2004; Morón/Medina 2016; Koskinen/Dam 2016; Kuzniz 2016; Morón 2010/in press). As a result, reflection on the boundaries around translation as a profession and the boundaryless ${ }^{6}$ nature of translation careers favors the development of creative careers. Rojo/Meseguer (2018) state: "as the number of qualified translators' increases, so does the need to develop creative strategies to achieve excellence and stay ahead of competitors" (2018: 79).

Finally, one of the last elements of added value presented here is teaching creativity. Trainers have tried to make the most of resources available and expert collaboration to produce innovative teaching experiences for trainees, who (as our results demonstrate) are very satisfied with the opportunity to face innovative, creative and original training challenges. In order to respond to market changes, trainers need to respond creatively and innovatively, especially in academic contexts in which mechanisms cannot be easily modified and market changes require some time to be accommodated (Koskinen/Dam 2016: 263; Morón/Lobato 2019).

6 Boundaryless careers is a concept developed by Arthur/Rousseau (1996) in the field of social sciences trying to understand work and employment dynamics, where today's workers' careers tend to be mobile and depend basically on personal decisions adopted by them. 


\section{References}

Aguayo, Natividad 2017: La interdisciplinariedad como elemento clave en la conceptualización de los Estudios de Traducción en el campo de conocimiento. In Skopos 8, 3-26.

ANECA 2006: Título de Grado en Traducción e Interpretación. Madrid: Agencia Nacional de Evaluación de la Calidad y Acreditación. Madrid: Ministerio de Educación y Ciencia.

Arthur, Michael B./Rousseau, Denise M. 1996: The Boundaryless career: A new employment principle for a new organizational era. Oxford: Oxford University Pres.

Boysen, Mikkel Snorre Wilms 2015: Does creativity rely on expertise? In Carmo, Mafalda (ed.), Education Applications \& Development: Advances in Education and Educational Trends. Portugal: inScience Press, 122-130.

Bundgaard, Kristine/Brøgger, Matilde Nisbeth 2017: Back translation: A neglected area in Translation Studies. European Society for Translation Studies Newsletter, 13-14.

Bundgaard, Kristine/Brøgger, Matilde Nisbeth 2018: Don't fix bad translations: A netnographic study of translators' understandings of back translation in the medical domain. In: Montalt, Vicent/Zethsen, Karen /Karwacka, Wioleta (eds.) Retos actuales y tendencias emergentes en traducción médica / Current challenges and emerging trends in medical translation. MonTI 10, 205-224.

Calvo, Elisa 2010: Análisis curricular de los estudios de Traducción e Interpretación en España: perspectiva del estudiantado. [online] https://hera.ugr.es/tesisugr/1852574x.pdf Granada: Universidad de Granada. (accessed 30 May 2019).

Calvo, Elisa 2015: Scaffolding translation skills through situated training approaches. In The Interpreter and Translator Trainer 9 (3), 306-322.

Calvo, Elisa 2018: From translation briefs to quality standards: Functionalist theories in today's translation processes. In The International Journal of Translation and Interpreting Research 10 (1), 18-32. [online] www.trans-int.org/ index.php/transint/article/view/639 (accessed 30 May 2019).

Calvo, Elisa/Morón, Marián 2006: What do translation students expect of their training in Spain. In Current trends in translation teaching and learning II: 105-118.

Colás, M. Pilar 1998: Los métodos descriptivos. In: Colás, M. Pilar/Buendía, Leonor (eds.), Investigación educativa. Sevilla: Alfar, 176-200.

Dam V., Helle/Brøgger, Matilde N./Zethsen K., Karen 2018: Moving Boundaries in Translation Studies, London: Routledge.

Di Giovanni, Elena 2008: Translations, Transcreations and Transrepresentations of India in Italian Media. In Méta: Journal des traducteurs, 53 (1), 26-43.

EMT (European Master's in Translation) 2017: Competence Framework 2017. [online] https://ec.europa.eu/info/sites/ info/files/emt_competence_fwk_2017_en_web.pdf (accessed 30 May 2019).

Ericsson, K. Anders 1998: The scientific study of expert levels of performance: General implications for optimal learning and creativity. In High Ability Studies: The Journal of the European Council for High Ability 9 (1), 75-100.

Gaballo, Viviana 2012: Exploring the boundaries of transcreation in specialized translation In ESP Across Cultures, 9: 95-113. [online] https://core.ac.uk/download/pdf/55276390.pdf (accessed 30 May 2019).

Gambier, Yves 2016: Rapid and Radical Changes in Translation and Translation Studies In International Journal of Communication 10, 887-906 [online] https://ijoc.org/index.php/ijoc/article/viewFile/3824/1570 (accessed 30 May 2019).

González-Davies, María/Scott-Tennent, Christopher 2005: A Problem-Solving and Student-Centred Approach to the Translation of Cultural References, In Méta, 50 (1): 160-179.

Gouadec, Daniel 2002; Profession: Traducteur. Paris: La Maison du Dictionnaire.

International Organization for Standardization 2015: ISO-17100. Translation services. Geneve: ISO.

Hernández, Roberto/Fernández, Carlos/Baptista, Pilar 2003: Metodología de la investigación. México: McGraw-Hill/ Interamericana Editores.

Katan, David 2016: Translation at the cross-roads: Time for the transcreational turn? Perspectives, 24 (3): 365-381.

Katan, David/Spinzi, Cinzia (eds.), 2014: Transcreation and the Professions. In Cultus: The International Journal of Mediation and Communication 7.

Kearns, John 2008: The academic and the vocational in translator education. In Kearns, John (ed.) Translator and Interpreter Training: Issues, Methods and Debates. London: Continuum International.

European commission. (European Commission, Directorate-General for Education and Culture) 2005: Effects on the European Economy Shortages of Foreign Language Skills in Enterprise. Executive Summary.

Kelly, Dorothy 2002: Un modelo de competencia traductora: bases para el diseño curricular. In Puentes 1: 9-20. 
Kelly, Dorothy 2005: A Handbook for Translator Trainers: a guide to reflective practice. Translation Practices Explained. Manchester: St. Jerome.

Ketola, Anne 2018: Picturebook Translation as Transcreation. In Juntunen, Hanne/ Sandberg Kirsi/Kocabaş, M. Kübra (eds.), Search of Meaning Literary, Linguistic, and Translational Approaches to Communication. Tampere: University of Tampere, 127-143.

Kiraly, Donald 2000: A Social Constructivist Approach to Translator Education: Empowerment from Theory to Practice. Manchester: St. Jerome Publishing.

Kiraly, Donald 2013: Towards a View of Translator Competence as an Emergent Phenomenon: Thinking Outside the Box(es) in Translator Education. In Kiraly, Donald/ Hansen-Schirra, Silvia/Maksymski, Karin (eds.) New Prospects and Perspectives for Educating Language Mediators, Tübingen: Narr Verlag, 197-224.

Kiraly, Donald 2016: Towards Authentic Experiential Learning in Translator Education. Göttingen: V\&R Academic Mainz University Press.

Koskinen, Kaisa/Dam V. Helle 2016: Academic boundary work and the translation profession: insiders, outsiders and (assumed) boundaries. In Jostrans, The Journal of Specialized Translation 25, 254-267.

Kussmaul, Paul 1995: Training the Translator. Amsterdam: John Benjamins.

Kuznik, Anna 2016: Work content of in-house translators in small and medium-sized industrial enterprises. Observing real work situations. In Jostrans, The Journal of Specialized Translation 25, 213-231.

Leggot, Dawn/Stapleford, Jane 2004a: Enhancing student awareness of employability skills through the use of progress files. Paper presented at the Conference Navigating the new landscape for languages conference, 30 June - 1 July 2004 [online]. https://www.llas.ac.uk/resources/paper/2279 (accessed 15 October 2008).

Leggot, Dawn/Stapleford, Jane 2004b: Language Student's Perceptions of their Employability Skills. In Higher London: CILT 9, 5 .

Malenova, Evgeniya D. 2017: Subtitling Practice: From Translation to Transcreation, Journal of Siberian Federal University. In Journal of Siberian Federal University. Humanities \& Social Sciences 10 (4), 526-536.

Mangell, Paul/Villavilla, Álvaro/Petrilli, Angela/Aoki, Makiko/Zhdanov, Vladimir (eds.) 2019: TAUS Transcreation Best Practices and Guidelines. Amsterdam: TAUS Signature Editions.

Mayoral, Roberto 2001: Aspectos epistemológicos de la Traducción. Castellón de la Plana: Publicaciones de la Universitat Jaume I.

Milton, John/Bandia, Paul F. 2009: Agents of Translation. Amsterdam/Philadelphia: John Benjamins.

Morón, Marián 2010: Percepciones sobre el impacto de la movilidad en la formación de traductores: el caso del Programa de Triple Titulación LAE (Lenguas Aplicadas Europa). Granada: Universidad de Granada [online]. http:// digibug.ugr.es/bitstream/10481/3496/1/18608620.pdf (accessed 30 May 2019).

Morón, Marián in press: From Translation Professionals to translation-related Professionals or 'non translators'. In Levey, David (ed.) Strategies and Analyses of Language and Communication in Multilingual and International Contexts. Cambridge: Cambridge Scholars Publishing.

Morón, Marián/Calvo, Elisa 2018: Introducing transcreation skills in translator training contexts: A situated projectbased approach. In Jostrans, The Journal of Specialised Translation 29, 126-148.

Morón, Marián/Lobato, Julia 2019: La transcreación de la moda à la mode: análisis de zonas de intervención en proyectos francés-español. In Onomazéin, Revista de Lingüistica, Filología y Traducción. Special Issue V - Tendencias actuales en traducción para el ámbito de la economía y los negocios, 40-59. DOI: 10.7764/onomazein.tradecneg.06.

Morón, Marián/Medina, Ana 2016: Professional competences of translators who do not 'translate': translators in professional fields of business internationalisation. In MonTI 10, 1-34.

Munday, Jeremy 2013 : Introducing translation studies : Theories and applications. London and New York: Routledge.

Musacchio, Maria Teresa/Zorzi, Virginia 2019: Scientific controversies and popular science in translation: Rewriting, Transediting or Transcreation? In Lingue Linguaggi 29, 481-507 [online]. http://siba-ese.unisalento.it/index.php/ linguelinguaggi/article/viewFile/20393/17350 (accessed 30 May 2019).

Nord, Christiane 1991: Text Analisis in Translation. Theory, Methodology and Didactic Application of a Model for Translation-Oriented Text Analysis. Amsterdam: Rodopi.

Østegaard Pedersen, Camilla 2015: Exploring the Concept of Transcreation: A Theoretical and Empirical Study of Transcreation with BMW as an Empirical Example. PhD Dissertation. Aarhus University [online]. http://pure.au.dk/ portal/files/61306039/Thesis.pdf (accessed 20 May 2019).

Pacte (Research Group) 2014: First results of PACTE group's experimental research on translation competence acquisition: The acquisition of declarative knowledge of translation. In Muñoz Martín, Ricardo (ed.) MonTI Special Issue 1: Minding Translation: 85-115. 
Pedersen, Daniel 2014: Exploring the concept of transcreation-transcreation as 'more than translation'? In Cultus. Journal of Intercultural Mediation and Communication 7, 57-71.

Pedersen, Daniel 2016: Transcreation in Marketing and Advertising: An Ethnographic Study. PhD Dissertation, Aarhus University: Denmark [online]. https://pure.au.dk/portal/files/99715430/Transcreation_in_Marketing_and_Advertising_An_Ethnographic_Study1.pdf (accessed 20 May 2019).

Pedersen, Daniel 2017: Managing transcreation projects: An ethnographic study. In Translation Spaces, 6 (1), 44-61.

Ray, Rebecca/Kelly, Nataly 2010: Reaching New Markets through Transcreation. Lowell: Common Sense Advisory. [online] https://docplayer.net/33272953-Reaching-new-markets-through-transcreation.html (accessed 30 May 2019).

Reilly, Dylan 2014: Transcreation: Intersections of Culture and Commerce in Japanese Translation and Localization. MA Dissertation. University of Pittsburgh. [online] http://d-scholarship.pitt.edu/27683/1/reillydb_etd.PDF (accessed 15 June 2019).

Reilly, Rosemary C. 2008: Is expertise a necessary precondition for creativity?: A case of four novice learning group facilitators. In Thinking Skills and Creativity 3 (1), 59-76.

Rike, Sissel Marie, 2013: Bilingual corporate websites - from translation to transcreation?, In Jostrans, The Journal of Specialised Translation 20, 68-85.

Risku, Hanna 2004: Migrating from translation to technical communication and usability. In Hansen, Gyde/Malmkjær, Kirsten/Gile, Daniel (eds.) Claims, Changes and Challenges in Translation Studies. London: John Benjamins, 181195.

Rojo, Ana/Meseguer, Purificación 2018: Creativity and Translation Quality: Opposing enemies or friendly allies? In Hermes. Journal of Language and Communication in Business, 57: 79- 96.

Runco, Mark 2012: Runco Creativity Assessment Battery (rCAB)(C [online]. https://www.creativitytestingservices. com/ (accessed 15 June 2019).

Sales, Dora. 2004: Puentes sobre el mundo: cultura, traducción y forma literaria en las narrativas de transculturación de José María Arguedas y Vikram Chandra, Berna: Peter Lang.

Sierra, Restituto 1998: Técnicas de investigación social: teoría y ejercicios. Madrid: Paraninfo.

Soriano, Inmaculada 2007: Evaluación de un programa de movilidad en formación de traductores: expectativas, experiencias y grado de satisfacción de los participantes, profesores y gestores de intercambio MGLU-UGR-ULPGC. Granada: Universidad de Granada [online]. http://hera.ugr.es/tesisugr/16713266.pdf (accessed 30 May 2019).

Tymoczko, Maria 2005: Trajectories of research in Translation Studies. In Meta 50(4), 1082-1097.

Tymoczko, Maria. 2007: Enlarging Translation, Empowering Translators. Manchester: St. Jerome.

Van de Meer, Jaap 2016: A To-Do List for the Translation Industry [online]. https://www.taus.net/blog/a-to-do-list-forthe-translation-industry (accessed 30 May 2019).

Way, Catherine 2008: Systematic assessment of translator competence: in search of Achilles' heel. In Kearns, John (ed.) Translator and interpreter training. London: Continuum, 88-103. 